\title{
Comparison of Motion History Image and Approximated Ellipse Method in Human Fall Detection System
}

\author{
Mohd Brado frasetyo*1 ${ }^{*}$, Elvira Sukma Wahyuni ${ }^{2}$, Hendra Setiawan ${ }^{3}$ \\ 1,2,3 Electrical Engineering Department, Universitas Islam Indonesia, Yogyakarta

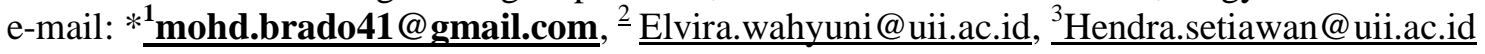

\begin{abstract}
Abstrak
Paper ini membandingkan dua metode untuk sistem pendeteksi jatuh pada manusia yaitu motion history image dan approximated ellipse. Penelitian dilakukan di dalam sebuah studio kecil menggunakan 4 kamera CCTV sebagai media perekaman data, kemudian pemrosesan data video dilakukan menggunakan software MATLAB. Percobaan dilakukan dengan menggunakan tiga jenis arah jatuh objek dan dua jenis pergerakan jatuh. Arah jatuh terdiri dari jatuh arah depan, samping, dan belakang. Pergerakan jatuh terdiri dari jatuh secara langsung dan jatuh tak langsung. Sementara itu, posisi awal dari objek adalah berdiri dan konstan. Hasil dari penelitian ini adalah metode motion history image memiliki akurasi sebesar $74.26 \%$ untuk jatuh secara langsung, dan $75.69 \%$ untuk jatuh tak langsung sedangkan metode approximated ellipse memiliki akurasi $56.85 \%$ untuk jatuh secara langsung, dan $61.81 \%$ untuk jatuh tak langsung. Hasil penelitian ini menunjukkan bahwa motion history image merupakan metode yang lebih baik dari approximated ellipse pada sistem pendeteksi jatuh pada manusia.
\end{abstract}

Kata kunci- Pemrosesan Citra, Pendeteksi Jatuh, Perbandingan Metode, Motion History Image, Approximated Ellipse.

\section{Abstract}

This paper compares two different methods in human fall detection system namely motion history image and approximated ellipse. Research has been done in small studio with 4 CCTV cameras as video data recorder, whereas video data are processed using MATLAB software. The experiment was carried out using three object's fall direction and two type of falling movement. The fall direction is consist of front, side, and back fall. Whereas the falling movement is consist of direct and indirect fall movement. Meanwhile, the object's initial position is standing and size of captured object is constant. The result of motion history image has accuracy $74.26 \%$ for direct falling movement, and $75.69 \%$ for indirect falling movement. Whereas approximated ellipse has accuracy $56.85 \%$ for direct falling movement, and $61.81 \%$ for indirect falling movement. Therefore, motion history image is better than approximated ellipse in human fall detection system.

Keywords - Image Processing, Human Fall Detection, Method Comparison, Motion History Image, Approximated Ellipse.

\section{INTRODUCTION}

Indonesia has a large elderly population, it is important to notice that $9.66 \%$ of elderly live alone without any family at home. An abnormal movements such as falls have a high risk for elderly's physical endurance, especially if elderly not treated quickly. So it takes a fall detection system using appropriate methods and algorithms to detect the movement.

Generally, there are 3 methods of fall detection that commonly used [1]. First, intrusive method which using sensors that attached on object's body. This method has been researched by 
[2], they are using accelerometer, microprocessor, and zigbee-3G network. Other research is conducted by [3], they are using accelerometer and zigbee. Second, non-intrusive method which using a device that is not in direct contact with object's body. This method has been done by [4], they are using Kinect sensor to detect object. Other research is conducted by [5], they are using camera to detect object. Third method is the combination of the first and second methods by using sensor that attached on object's body and simultaneously using a device that is not in direct contact with object's body (compound). This method has been done by [3], they are using accelerometer and zigbee. Other research is conducted by [6], they are using camera and accelerometer. Based on [2], the most appropriate human telemonitoring method is nonintrusive method (by using a camera (image processing), Kinect and access point) that do not interfere the comfort and elderly activities as the subject of supervision.

Related to non-intrusive using camera, there are several methods to detect the movement of a person's fall using image processing, we are using motion history image (MHI), and approximated ellipse to system. MHI and approximated ellipse are good methods for detecting falling motions, since they count important parameters in falling motion like movement speed and direction of motion, these two parameters are important to know whether a person is falling or not. This paper compares how the performance of the human fall detection system uses each of the methods separately.

Fall detection system using motion history image (MHI) and approximated ellipse have been done by some researchers before. First, research by Caroline Rougier et al, this research about how to detect someone fall by using computer vision system. The method is using Motion History Image (MHI) and Human Shape Variation which detects pixel changes in video sequence images so that it can detect a person's movement changes, when the movement is very fast and suddenly stop then someone is considered to fall. The result is the system can detect people falling and can differentiate with daily movement. However, this system uses only 1 camera so that not all object movement can be detected properly [7].

Research conducted by Nuttapong Worrakulpanit et al, this research is on how to detect someone fall by looking at changes in movement speed and changes of object's body position. The method used is Motion History Image (MHI), the fall detection algorithm based on the change of two parameters i.e. $C_{\text {motion }}$ that representing coefficient of object motion and Sigma_ $\theta$ that representing shape orientation on camera's parallel optical axis. However, the Sigma_ $\theta$ value is not enough to detect a person's body position change because it only detects changes in movement parallel to the camera's optical axis [8].

Another study conducted by Suad Albawendi et al, this study also uses Motion History Image (MHI) as a motion detection object. However, in this study they use a camera that is placed exactly in front of the object, therefore the camera visibility that they use is limited [9].

\section{METHODS}

\subsection{Motion History Image}

Motion history image is a method to detect the movement of objects, this method detects movement based on pixel changes. The movement of an object is taken from a video that has been divided into several sequence images. Motion History Image (MHI) was first introduced by Bobick and Davis [10]. The step to build a MHI is extract the binary sequence of the object movement $\mathrm{D}(\mathrm{x}, \mathrm{y}, \mathrm{t})$ from the original image $\mathrm{I}(\mathrm{x}, \mathrm{y}, \mathrm{t})$ using the image-differencing method [7]. Then compute $H_{t}$ each pixel using equation 1 , in time range $\mathrm{t}(1 \leq \tau \leq \mathrm{n})$.

$$
H_{\tau}(x, y, t)=\left\{\begin{array}{lr}
\tau & \text { if } D(x, y, t)=1 \\
\max \left(0, H_{\tau}(x, y, t-1)-1\right) & \text { otherwise }
\end{array}\right.
$$

Where :

IJCCS Vol. 13, No. 2, April 2019: 199-208 
$x \quad=$ Position of pixels in $\mathrm{x}$ coordinates.

$y \quad=$ Position of pixels in $\mathrm{y}$ coordinates.

$H_{\tau}(x, y, t)=$ Motion History Image (MHI).

$D(x, y, t)=$ Motion of binary sequence from object.

The result is a scalar value of the image where the movement of the object will change to white.

\section{2 Approximated Ellipse}

Objects will be predicted using ellipse using moments. An ellipse is defined by some parameters, they are centroid $(x, y)$, orientation, major semi-axis a and minor semi-axis $\mathrm{b}$ [7]. For a continuous image, the moments values are derived from equation 2:

$$
m_{p q}=\int_{-\infty}^{\infty} \int_{-\infty}^{\infty} x^{p} y^{q} f(x, y) d x d y
$$

Where :

$$
\begin{array}{ll}
m_{p q} & =\text { Moments value. } \\
p, q & =0,1,2 .
\end{array}
$$

Centroid of ellipse is obtained by calculating the coordinates of the center of mass with first and zero spatial order moments using equation 3 .

$$
\bar{x}=\frac{m 10}{m 00} ; \bar{y}=\frac{m 01}{m 00}
$$

Where :

$\begin{array}{ll}\bar{x} & =\text { Centroid in } \mathrm{x} \text { coordinates. } \\ \bar{y} & =\text { Centroid in } \mathrm{y} \text { coordinates. }\end{array}$

Centroid $(x, y)$ is used to calculate central moments $\mu_{p q}$ using equation 4.

$$
\mu_{p q}=\int_{-\infty}^{\infty} \int_{-\infty}^{\infty}(x-\bar{x})^{p}(y-\bar{y})^{q} f(x, y) d x d y
$$

The angle between the main axis of the object and the horizontal axis $\mathrm{x}$ gives the orientation of the ellipse $\theta$, and can be calculated by the central moments of order 2 from equation 5 .

$$
\theta=\frac{1}{2} \tan ^{-1}\left(\frac{2 \mu_{11}}{\mu_{20}-\pi_{02}}\right)
$$

To get the major semi-axis a and minor semi-axis b of ellipse, we must calculate $I_{\min }$ and $I_{\max }$, ie the smallest moment of inertia and the moment of greatest inertia [3]. This value can be calculated by evaluating the eigenvalue of the covariance matrix $[J]$ from equation 6 .

$$
J=\left(\begin{array}{ll}
\mu_{20} & \mu_{11} \\
\mu_{11} & \mu_{02}
\end{array}\right)
$$

The eigenvalue of the matrix $J$ is $I_{\min }$ and $I_{\max }$ which is calculated by equation 7 .

$$
\begin{aligned}
& I_{\text {min }}=\mu_{20}-\mu_{02}-\frac{\sqrt{\left(\mu_{20}-\mu_{02}\right)^{2}+4 \mu_{11}{ }^{2}}}{2} \\
& I_{\text {max }}=\mu_{20}+\mu_{02}-\frac{\sqrt{\left(\mu_{20}-\mu_{02}\right)^{2}+4 \mu_{11}^{2}}}{2}
\end{aligned}
$$

Where :

$$
\begin{aligned}
& I_{\min }=\text { Minimum value of moment inertia. } \\
& I_{\max }=\text { Maximum value of moment inertia. }
\end{aligned}
$$


Then the major semi-axis a and minor semi-axis $\mathrm{b}$ are calculated by equation 8 .

$$
\begin{aligned}
& a=\left(\frac{4}{\pi}\right)^{\frac{1}{4}}\left(\frac{\left(I_{\max }\right)^{3}}{I_{\min }}\right)^{1 / 8} \\
& b=\left(\frac{4}{\pi}\right)^{\frac{1}{4}}\left(\frac{\left(I_{\min }\right)^{3}}{I_{\max }}\right)^{1 / 8}
\end{aligned}
$$

Where :

$$
\begin{array}{ll}
a & =\text { Major semi-axis } \mathrm{a} . \\
b & =\text { Minor semi-axis } \mathrm{b} .
\end{array}
$$

With $\mathrm{a}$ and $\mathrm{b}$ we can determine the ratio of ellipse $\rho$ by using equation 9 .

$$
\rho=\frac{a}{b}
$$

\section{3 Algorithm Threshold}

Motion history image will be analyzed using the fall detection system algorithm, which is based on the speed of the object movement $\left(c_{\text {motion }}>0.6\right)$ [7]. The threshold is designed by looking at the parameter response of some video data, then selecting the value with the highest accuracy.

To calculate the value of coefficient of object motion is using equation 10 .

$$
C_{\text {motion }}=\frac{\sum \text { pixel }_{(x, y)} \in{\text { blob } H_{\tau}(x, y, t)}}{\# \text { pixels } \in \text { blob }}
$$

Where :

$$
\begin{aligned}
& C_{\text {motion }}=\text { Coefficient of object motion } \\
& \text { Blob }=\text { Blob } \text { of pixel. }
\end{aligned}
$$

Approximated ellipse will analyzed using the change of body shape of the object (Change of Sigma_ $\rho$ or Sigma_ $\theta<-0.1$ ). The value is obtained from equation 11.

$$
\begin{aligned}
& \text { Sigma_} \theta=\sigma_{\theta} \\
& \text { Sigma_} \rho=\sigma_{\rho}
\end{aligned}
$$

Where :

Sigma_ $\theta=$ The orientation standard deviation.

Sigma_ $\rho=$ The ratio standard deviation.

If a person falls perpendicularly to the camera optical axis, than the orientation will change significantly. If a person fall parallel to the camera optical axis, than the ratio will change significantly.

\subsection{System Models}

The fall detection system is using some variable of data to test the accuracy of each method, firstly is the direction of falling object and the second one is object's movement type. The direction of falling object is divided into three, they are front, side, and back fall. Whereas the object's movement type is divided into two types namely direct fall and indirect fall. Direct fall is object falling directly without obstacles, and indirect fall is object falling indirectly using knee. Figure 1 shows the illustration of object's movement types [11]. 


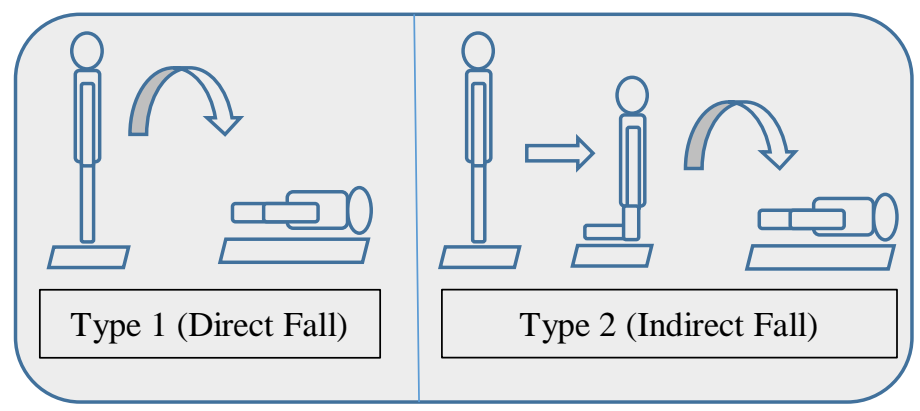

Figure. 1 Object's Falling Movement Types

System performance was tested in a mini studio at computer laboratory Universitas Islam Indonesia. We are recording the data using 4 CCTV cameras that have been installed in every corner of the studio. The dimensions of studio is 9 (Length) x 5.1 (Width) x 2.75 (Height) $\mathrm{m}$. In studio, there are several others object like table and chair, so there is possibility of object to not being captured by CCTV cameras. The CCTV cameras that has been used has resolution $1280 \times 720$ pixel, this resolution is huge and data being processed are too large, so the system is implemented in offline mode. Figure 2 shows the studio condition captured by all of CCTV cameras.

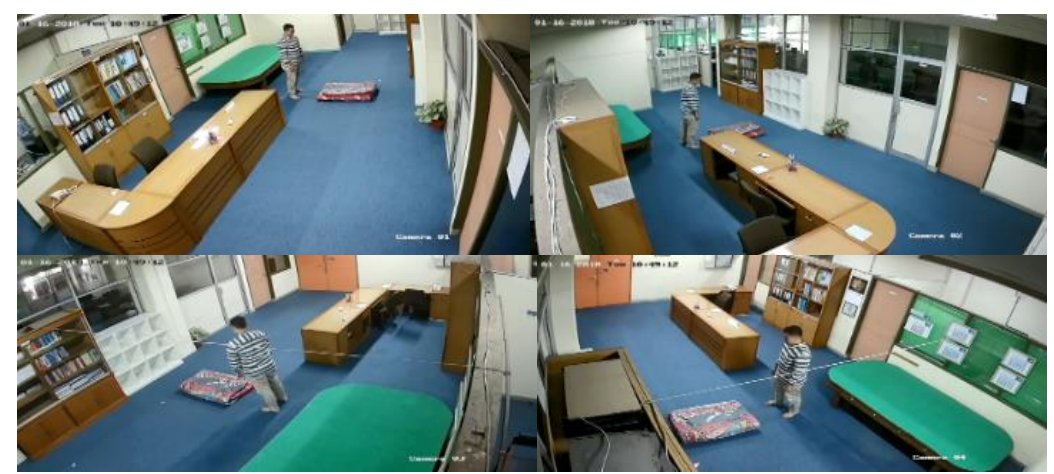

Figure 2 Result of Recorded Data from 4 CCTV Camera

\section{RESULT AND DISCUSSION}

\subsection{Motion History Image (MHI)}

First of all, we have a test the fall detection system using motion history image algorithm. We converting the data of each video frame into MHI. This process has several stages which is foreground detection, filtering blob, and build MHI. The result of motion history

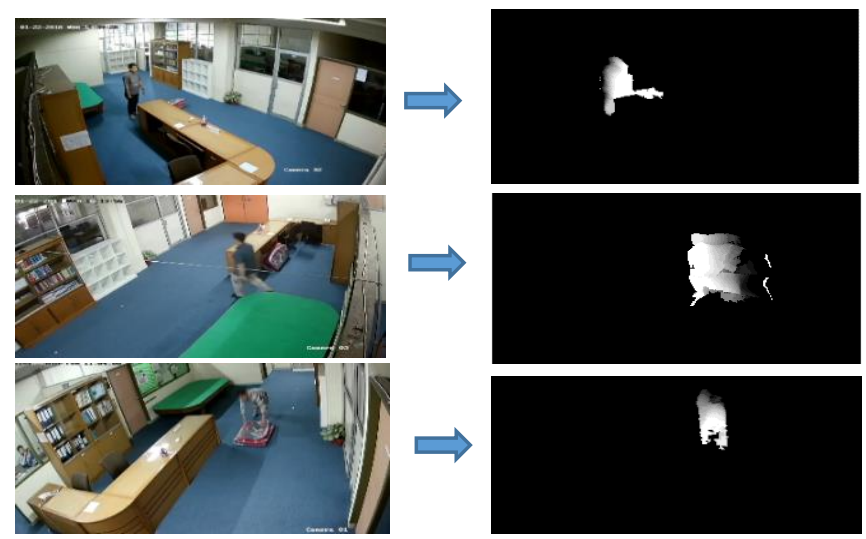

Comparison of Motion History Image and Approximated ... (Mohammad Brado Frasetyo) 
image is shows at figure 3.

Figure 3 Motion History Image Result

After all of conversion process is done, we test the motion history image method on human fall detection system. The experiment has been done using some various of data, they are using different direction and falling movement, the data also tested using all of CCTV cameras, therefore the total of data that has been tested are 24 data. Table 1 show the result of fall detection system using motion history image method.

Table 1. Fall Detection Result with MHI.

\begin{tabular}{|l|l|r|r|}
\hline Camera & Direction & Direct (\%) & Indirect (\%) \\
\hline \multirow{4}{*}{ Cam 1 } & Front & 62.5 & 75 \\
\cline { 2 - 4 } & Side Fall & 78.5 & 100 \\
\cline { 2 - 4 } & Back Fall & 83.33 & 83.33 \\
\hline \multirow{4}{*}{ Cam 2 } & Front & 68.75 & 75 \\
\cline { 2 - 4 } & Side Fall & 64.3 & 50 \\
\cline { 2 - 4 } & Back Fall & 66.6 & 83.33 \\
\hline \multirow{4}{*}{ Cam 3 } & Front & 87.5 & 100 \\
\cline { 2 - 4 } & Side Fall & 92.8 & 50 \\
\cline { 2 - 4 } & Back Fall & 83.33 & 83.33 \\
\hline \multirow{4}{*}{ Cam 4 } & Front & 75 & 75 \\
\cline { 2 - 4 } & Side Fall & 78.5 & 50 \\
\cline { 2 - 4 } & Back Fall & 50 & 83.3 \\
\hline Average & & 74.26 & 75.69 \\
\hline
\end{tabular}

Table 1 shows the accuracy of human fall detection system using motion history image method is $74.26 \%$ for direct falling movement, and $75.69 \%$ for indirect falling movement. Table also shows that all of CCTV cameras are works on capturing and detecting object's pixel.

\subsection{Approximated Ellipse}

We testing fall detection system using approximated ellipse algorithm. After all of conversion process is done, we test the approximated ellipse method on human fall detection system. The experiment has been done using some various of data, they are using different direction and falling movement, the data also tested using all of CCTV cameras, therefore the total of data that has been tested are 24 data. Table 2 shows the result of fall detection system using approximated ellipse method.

Table 2. Fall Detection Result with Approximated Ellipse.

\begin{tabular}{|l|l|r|r|}
\hline \multirow{3}{*}{ Camera } & Direction & Direct (\%) & Indirect (\%) \\
\hline \multirow{4}{*}{ Cam 1 } & Front & 62.5 & 75 \\
\cline { 2 - 4 } & Side Fall & 71.4 & 100 \\
\cline { 2 - 4 } & Back Fall & 66.6 & 83.33 \\
\hline \multirow{4}{*}{ Cam 2 } & Front & 31.25 & 25 \\
\cline { 2 - 4 } & Side Fall & 50 & 50 \\
\cline { 2 - 4 } & Back Fall & 50 & 50 \\
\hline \multirow{3}{*}{ Cam 3 } & Front & 68.75 & 100 \\
\cline { 2 - 4 } & Side Fall & 71.4 & 50 \\
\cline { 2 - 4 } & Back Fall & 66.6 & 83.33 \\
\hline
\end{tabular}




\begin{tabular}{|l|l|r|r|}
\hline Camera & Direction & Direct (\%) & \multicolumn{2}{|l|}{ Indirect (\%) } \\
\hline \multirow{4}{*}{ Cam 4 } & Front & 43.75 & 25 \\
\cline { 2 - 4 } & Back Fall & 50 & 50 \\
\cline { 2 - 4 } & Side Fall & 50 & 50 \\
\hline Average & & 56.85 & 61.81 \\
\hline
\end{tabular}

Table 2 shows the accuracy of human fall detection system using motion history image method is $56.85 \%$ for direct falling movement, and $61.81 \%$ for indirect falling movement. Table also shows that all of CCTV cameras are works on capturing and detecting object's pixel.

\subsection{Error Data Analysis}

There are several errors that caused by the movement that have a similar changes of parameter like a fall, such as object runs quickly then stops, object sits extremely, or presence of excessive shadow intensity.

First, the error is caused by object runs quickly then stop that shown at figure 4 , and the parameter changes result is shown at figure 5 .
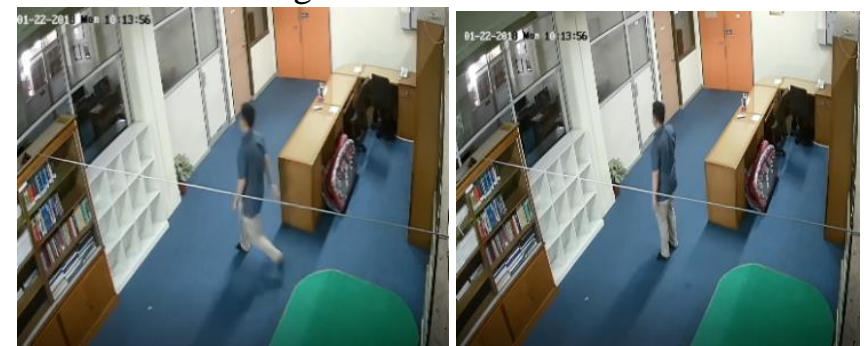

Figure 4 Object run quickly then stop

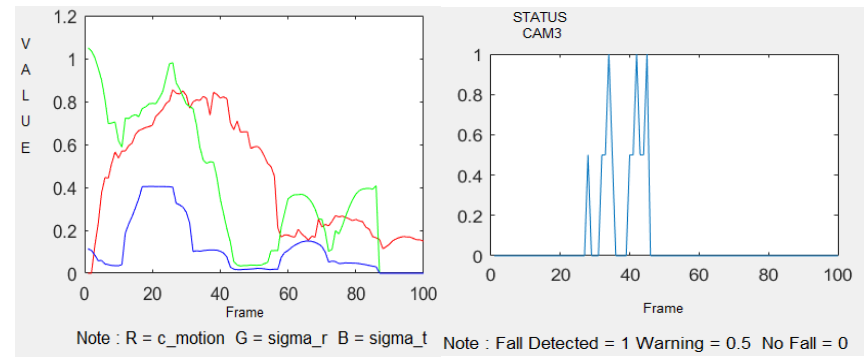

Figure 5 Graphic of parameter changes on non-fall data

Figure 4 show the parameter changes when object runs quickly then stop, the result is parameter has a similar changes like a fall data. At frame 0 to 25 object is running quickly so $C_{\text {motion }}$ parameter value is high and reach the threshold, then at frame 26 to 45 object suddenly stop then causing all of parameters value such as Sigma_O and Sigma_ $\rho$ are imitating like a fall data. Therefore, when object moving so quick then stop causing an error on human fall detection algorithm.

Other error is caused by movement when object is sitting extremely, the movement is look like figure 6 , and the parameter changes result is shown at figure 7.
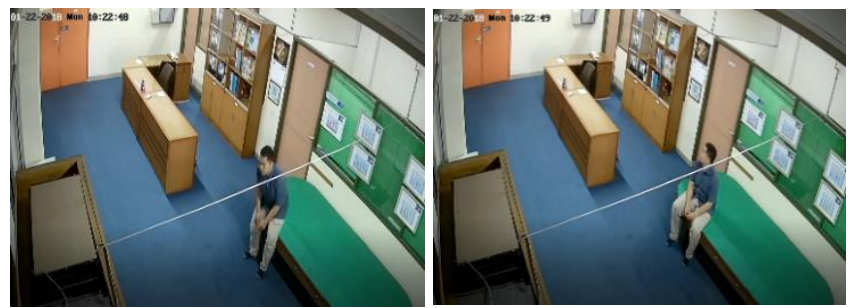

Figure 6 Object sitting extremely movement 


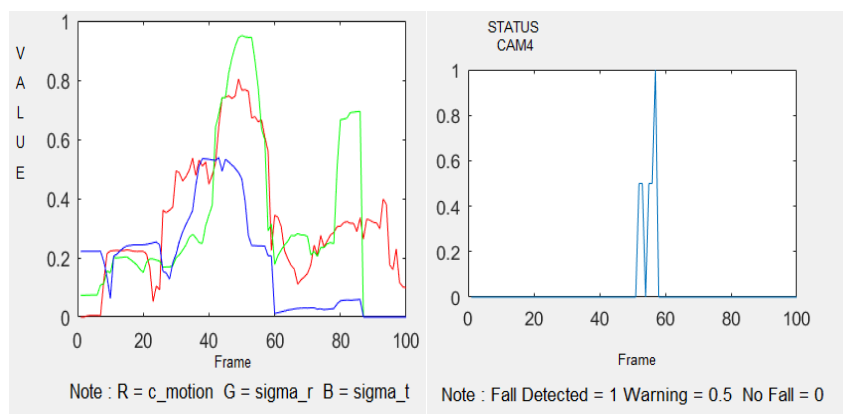

Figure 7 Graphic of parameter changes on non-fall data

Figure 7 show the parameters value changes when object was sitting extremely, parameter has a similar changes like a fall movement data. At frame 50 to 60, parameter generate the response like a fall movements parameter, this is caused by object motion has a high speed change, so $C_{\text {motion }}$ value is higher than algorithm threshold. As well as when object direction is changing from stand up to sit down, Sigma_ $\theta$ and Sigma_ $\rho$ value will reach the threshold too. Therefore, when object sitting down with extreme speed, the algorithm will consider the data as a fall data.

The last error is caused by the light intensity, our result is shown at figure 8 .
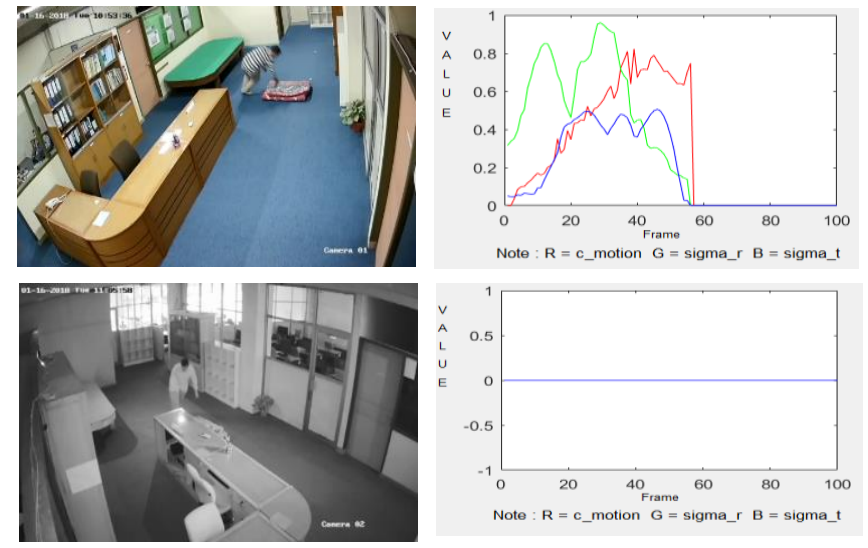

Figure 8 System's response on different light intensity.

The results show that when intensity of light is bright algorithm can detect fall well, because the camera can catch the parameter changes more clearly and only get a little disturbance from the shadows of object, so the parameters generated become more accurate. But when light intensity is dark, fall can't be detected. Because, pixel was not captured by the camera so the $C_{\text {motion }}$ parameter does not appear.

\subsection{System Limitation}

The fall detection system algorithms are influenced by some conditions that cause the performance to be disturbed. First, object's position that should in the center of the room because when object is too close to camera, every little disturbance like shadow will captured and causing an error. As well as when object is too far from camera, the object can't be captured well because of object's pixel area is too small. Second, the existence of other objects that block CCTV camera's vision, so when object position is behind other object the pixel changes can't be captured and causing algorithm not working well. Third, the speed of falling objects. The algorithm is based on motion speed and object shape direction, if motion speed is slow so the algorithm threshold can't be reached. Last conditions that disturbing the algorithm is light intensity, when light is too dark, the camera can't capturing object movement well. Despite of these limitation, the fall detection system has a good performance against the difference direction of fall and difference color between objects and background. 


\section{CONCLUSSION}

Motion history image is an image processing method to detect a fall by detecting the motion of an object, the resulting parameter is $c_{\text {motion }}$ with a $0-100 \%$ scale, while $0 \%$ means no motion and $100 \%$ means full motion from object. Approximated ellipse is an image processing method that detects the orientation of the human shape of the object, the parameters generated by this method are Sigma_ $\theta$ and $S_{i g m a} \rho$ that representing the change of the human shape from object.

Motion history image (MHI) method has better performance than approximated ellipse in human fall detection system. MHI has accuracy $74.26 \%$ for direct falling movement, and $75.69 \%$ for indirect falling movement. Whereas approximated ellipse has accuracy $56.85 \%$ for direct falling movement, and $61.81 \%$ for indirect falling movement. The MHI method has better accuracy is caused by the parameter that has been processed, MHI detecting motion speed that means if object moving quickly like fall, object will indicated as fall movement. Whereas approximated ellipse's parameter is detecting the change of object's shape, so if object is changing his direction, object will indicated as falling data even though it is not a falling movement actually.

There are some features that need to be improved for future development of the system. First, adding better filter at the preprocessing process that will improving motion history image result. Second, rework the algorithm for better accuracy. Third, implementing image compression for faster process, because the system is computing a big amount of data.

\section{ACKNOWLEDGEMENT}

The authors would like to thank to directorate research, technology and general high education (RISTEKDIKTI) Indonesia for supporting this project.

\section{REFERENCES}

[1] Setiawan Hendra, and Elvira Sukma Wahyuni, "Comparison of Some Methods for the Elderly Patient Telemonitoring System," Kinetik: Game Technology, Information System, Computer Network, Computing, Electronics, and Control, Vol. 3, No. 3, 2018 [Online]. Available : http://kinetik.umm.ac.id/index.php/kinetik/article/view/627 [Accessed : 16-Oct-2018].

[2] Ye Z., Li Y., Zhao Q., \& Liu X., "A falling detection system with wireless sensor for the elderly people based on ergonomics," International Journal of Smart Home, 8(1), pp.187196, 2014 [Online].

Available : https://www.semanticscholar.org/paper/A-Falling-Detection-System-withwireless-sensor-for-Ye-Li/3d5282d2705f6f9dcbc6b9dfb8b2585a92b2da0b [Accessed : 10-Oct-2018]

[3] Dias P. V. G., Costa E. D. M., Tcheou M. P., \& Lovisolo F., "Fall detection monitoring system with position detectionfor elderly at indoor environments under supervision," In communications (LATINCOM), 8th IEEE Latin-American Conference on, pp. 1-6, 2016 [Online].

Available : https://ieeexplore.ieee.org/document/7811576[Accessed : 16-Oct-2018].

[4] Santiago J., Cotto E., Jaimes L. G., \& Vergara-Laurens I. "Fall detection system for the elderly," In Computing and Communication Workshop and Conference (CCWC), 2017 IEEE 7th Annual, pp. 1-4, 2017 [Online].

Available :https://ieeexplore.ieee.org/document/7868363 [Accessed : 16-Oct-2018]. 
[5] Hwang S., Ahn D., Park H., \& Park T. "Maximizing Accuracy of Fall Detection and Alert Systems Based on 3D Convolutional Neural Network," In Proceedings of the Second International Conference on Internet-of-Things Design and Implementation, pp. 343-344, ACM, 2017 [Online].

Available : https://ieeexplore.ieee.org/document/7946918[Accessed : 16-Oct-2018].

[6] Castillo J. C., Carneiro D., Serrano-Cuerda J., Novais, P., Fernández-Caballero A., \& Neves J. "A multi-modal approach for activity classification and fall detection," International Journal of Systems Science, 45(4), pp.810-824, 2014 [Online].

Available:https://www.researchgate.net/publication/262171738_A_Multi-

Modal_Approach_for_Activity_Classification_and_Fall_Detection [Accessed : 14-Oct2018].

[7] Rougier Caroline, et al., "Fall detection from human shape and motion history using video surveillance," Advanced Information Networking and Applications Workshops, 2007, AINAW'07. 21st International Conference on. Vol. 2, IEEE, 2007 [Online].

Available :https://ieeexplore.ieee.org/document/4224216 [Accessed : 12-Oct-2018].

[8] Worrakulpanit, Nuttapong, and Pranchalee Samanpiboon, "Human fall detection using standard deviation of C-motion method," Journal of Automation and Control Engineering, Vol. 2, No. 4, 2014 [Online].

Available:http://www.joace.org/uploadfile/2014/0114/20140114120626761.pdf [Accessed : 12-Oct-2018].

[9] Albawendi, Suad, et al., "Video based fall detection with enhanced motion history images," Proceedings of the 9th ACM International Conference on Pervasive Technologies Related to Assistive Environments, ACM, 2016 [Online].

Available:https://dl.acm.org/citation.cfm?id=2935832 [Accessed : 12-Oct-2018].

[10] Bobick Aaron F., and James W. Davis, "The recognition of human movement using temporal templates." IEEE Transactions on pattern analysis and machine intelligence, Vol. 23, No. 3, 2001 [Online].

Available : https://ieeexplore.ieee.org/document/910878 [Accessed : 10-Oct-2018].

[11] ES Wahyuni, et al. "Combination of motion history image and approximated ellipse on human fall detection system," $8^{\text {th }}$ International Conference on Intelligent Systems, Modelling and Simulation ISMS2018, IJSST, Vol. 19, No. 3, 2018 [Online].

Available:http://ijssst.info/Vol-19/No-3/paper13.pdf [Accessed : 11-Oct-2018]. 